\title{
Activation of the prostaglandin D2 metabolic pathway in Crohn's disease: involvement of the enteric nervous system
}

Anne-Gaelle Le Loupp ${ }^{1,2,3,4}$, Kalyane Bach-Ngohou ${ }^{1,2,3,4}$, Arnaud Bourreille 1,2,3,4 Hélène Boudin 1,2,3, Malvyne Rolli-Derkinderen ${ }^{1,2,3}$, Marc G. Denis ${ }^{1,2,3,4}$, Michel Neunlist ${ }^{1,2,3}$ and Damien Masson ${ }^{1,2,3,4^{*}}$

\begin{abstract}
Background: Recent works provide evidence of the importance of the prostaglandin D2 (PGD2) metabolic pathway in inflammatory bowel diseases. We investigated the expression of PGD2 metabolic pathway actors in Crohn's disease (CD) and the ability of the enteric nervous system (ENS) to produce PGD2 in inflammatory conditions,
\end{abstract}

Methods: Expression of key actors involved in the PGD2 metabolic pathway and its receptors was analyzed using quantitative reverse transcriptase polymerase chain reaction (qRT-PCR) in colonic mucosal biopsies of patients from three groups: controls, quiescent and active CD patients. To determine the ability of the ENS to secrete PGD2 in proinflammatory conditions, Lipocalin-type prostaglandin D synthase (L-PGDS) expression by neurons and glial cells was analyzed by immunostaining. PGD2 levels were determined in a medium of primary culture of ENS and neuro-glial coculture model treated by lipopolysaccharide (LPS).

Results: In patients with active CD, inflamed colonic mucosa showed significantly higher COX2 and L-PGDS mRNA expression, and significantly higher PGD2 levels than healthy colonic mucosa. On the contrary, peroxysome proliferator-activated receptor Gamma (PPARG) expression was reduced in inflamed colonic mucosa of CD patients with active disease. Immunostaining showed that L-PGDS was expressed in the neurons of human myenteric and submucosal plexi. A rat ENS primary culture model confirmed this expression. PGD2 levels were significantly increased on primary culture of ENS treated with LPS. This production was abolished by AT-56, a specific competitive L-PGDS inhibitor. The neuro-glial coculture model revealed that each component of the ENS, ECG and neurons, could contribute to PGD2 production.

Conclusions: Our results highlight the activation of the PGD2 metabolic pathway in Crohn's disease. This study supports the hypothesis that in Crohn's disease, enteric neurons and glial cells form a functional unit reacting to inflammation by producing PGD2.

\section{Background}

Inflammatory bowel diseases (IBD) are described as multifactorial pathologies with an uncontrolled immune response leading to inflammation in genetically predisposed individuals. IBD etiologies remain unresolved $[1,2]$. The role of prostaglandins (PG) in its pathogenesis was first suggested in 1977 [3]. Previous studies have reported high

\footnotetext{
* Correspondence: damien.masson@chu-nantes.fr

'INSERM Unité 913, 1 rue Gaston Veil, Nantes F-44035, France

2Université Nantes, 1 quai de Tourville, BP 13522, Nantes F-44035, France

Full list of author information is available at the end of the article
}

levels of PGD2 in animal models of colitis [4, 5] and in colonic mucosal biopsies of patients with a history of ulcerative colitis (UC) [6]. PGD2 synthesis is derived from prostaglandin $\mathrm{H} 2$ (PGH2) through prostaglandin D synthase (PGDS). PGH2 is derived from arachidonic acid by cyclooxygenases (COX), which exist in two isoforms: COX1 and COX2. COX1 is expressed constitutively in most cell types, whereas COX2 is induced by inflammatory stimuli such as bacterial endotoxin and proinflammatory cytokines. Two distinct PGDS have also been identified: hematopoietic PGDS (HPGDS) and lipocalintype PGDS (L-PGDS). Similarly to COX2, L-PGDS but 
not HPGDS is known to be inducible in inflammatory conditions $[7,8]$. While overexpression of microsomal prostaglandin E synthase-1 and the proinflammatory role of PGE2 have been well described in IBD [9], the role of PGD2 in IBD remains debated and there have been no reports on PGD2 in Crohn's Disease (CD). Ajuebor et al. demonstrated that PGD2 reduced granulocyte infiltration during experimental colitis [5]. Vong et al. reported high levels of PGD2 in the colonic tissue of patients with quiescent $\mathrm{CD}$ [6]. Some of the anti-inflammatory properties attributed to PGD2 may be related to the effects of its metabolite, 15-deoxy- $\Delta^{12,14}$-prostaglandin J2 (15dPGJ2), which has been shown to exert potent anti-inflammatory effects in animal models through activation of its receptor PPARG [10, 11]. Conversely, Hokari et al. suggested that LPGDS plays a proinflammatory role in the development of colitis in clinical and experimental studies [12]. They reported that the level of L-PGDS mRNA expression was increased in UC patients in parallel with disease activity. However, changes in PGD2 production or in the expression of enzymes involved in its synthesis during $C D$ are currently unknown.

Although immune cells are central producers of cytokines and prostaglandins; the cells of the mucosa are also known to be able to contribute to this production [13]. The ENS is a major constituent of the intestinal mucosal microenvironment. The ENS, composed of enteric neurons and enteric glial cells (EGCs), together with the intestinal epithelial barrier (IEB) is a functional entity, the digestive neuronal-glial-epithelial unit, based on the physical proximity and paracrin relationship between its components [14]. Indeed, the ENS is known to regulate the gut homeostasis process and, in particular, intestinal epithelial barrier functions, via the release of various mediators [14]. Recent studies have shown that the ENS is able to sense inflammatory stressors and respond by secreting various cytokines or chemokines [15, 16]. Furthermore, various studies have described abnormalities of the ENS in $\mathrm{CD}$ and have suggested a role of the ENS in the pathogenesis of IBD [17-22]. Recently, we have demonstrated that the EGCs of the ENS are involved in controlling intestinal epithelial functions through secretion of 15dPGJ2 [23]. However, the ability of the ENS to produce PGD2 and its modulation by inflammation remains unknown.

Based on these findings, our aims were to investigate expression of key actors of the PGD2 metabolic pathway in colonic mucosal biopsies of patients with $\mathrm{CD}$ and to evaluate the ability of the ENS to produce PGD2 in proinflammatory conditions.

\section{Methods}

\section{Patient selection}

Tissue samples were collected from colonic biopsies of patients with $\mathrm{CD}$. Thirty patients with $\mathrm{CD}$ treated at the
Department of Gastroenterology (Nantes University Hospital, France) were included in this study. Colonic biopsies were obtained and stored in the bio-collection of the "Institut des Maladies de l'Appareil Digestif (IMAD)". The clinical and demographic data were collected and recorded in a computerized database securely coupled to the biological collection. This bio-collection was approved and registered by the French Ministry of Science and Research "DC-2008-402". CD was diagnosed on the basis of clinical and endoscopic criteria. Fifteen quiescent disease patients and fifteen active disease patients, with acute or chronic inflammation, were included in this study. Two biopsies were collected from patients with active disease, one in an inflamed zone and one in a normal zone. Colonic biopsy specimens from normal mucosa were collected from fifteen patients with colonic polyps and were used as controls. All tissues were processed according to the French Guidelines for Research on Human Tissues (Agence Nationale d'Accréditation 2001). The characteristics of patients included are given in Table 1. After collection, biopsies were immediately immersed in RA1 buffer (Macherey Nagel, Hoerdt, France) and stored at $-80{ }^{\circ} \mathrm{C}$ before real-time PCR analysis. Samples intended for PGD2 determination were stored at $-80{ }^{\circ} \mathrm{C}$ until time of use.

For immunofluorescence staining, tissue specimens were collected from patients who underwent surgery for colonic adenocarcinoma (four colonic specimens from two patients were stained). Patients gave their informed and written consent for the biopsy studies. Specimens were taken at a distance from the tumor, in macroscopically and histologically normal areas, and immediately processed in the Pathology Department. According to the guidelines of the French Ethics Committee for Research on Human Tissues, these specimens were considered as "residual tissues", not relevant to pathological diagnosis. Tissue samples were subsequently fixed in $4 \%$ paraformaldehyde for 3 hours at room temperature. Following several washes in phosphate buffer saline (PBS), tissue was pinned and whole mounts of mucosal and submucosal plexus were obtained by microdissection under a microscope SZ3060 (Olympus, Rungis, France), as previously described [24].

\section{Cell culture and treatments}

\section{Primary culture of the enteric nervous system}

Primary culture of the rat ENS was performed as previously described [25]. Experiments were compliant with journal policies and UK regulations on animal experimentation as described by Drummond [26]. Pregnant Sprague-Dawley rats at stage E15 were purchased (CERJ, Le Genest St Isle, France) and manipulated in compliance with French institutional guidelines. These procedures were approved by the local institutional 
Table 1 Clinical characteristics and treatments - Crohn's disease patients at the time of study inclusion. Values are given as the mean (minimum-maximum) for continuous variables and numbers (\%) for categorical variables

\begin{tabular}{llll}
\hline & $\begin{array}{l}\text { Quiescent } \\
\text { Crohn's disease }\end{array}$ & $\begin{array}{l}\text { Active Crohn's } \\
\text { disease }\end{array}$ & Controls \\
\hline Cases & 15 & 15 & 15 \\
Age, years & $36(18-63)$ & $37(21-76)$ & $55(38-76)$ \\
Sex female/male & $9 / 8$ & $11 / 4$ & $4 / 11$ \\
Age at diagnosis, years & $30(19-60)$ & $26(15-58)$ & \\
$\begin{array}{l}\text { Duration of the disease, } \\
\text { years }\end{array}$ & $7(1-21)$ & $12(1-26)$ & \\
$\begin{array}{l}\text { Current treatment } \\
\text { No medication }\end{array}$ & $1(7 \%)$ & $5(33 \%)$ & \\
$\begin{array}{l}\text { 5-ASA/Salazopyrin/ } \\
\text { Azathioprine } \\
\text { Corticosteroids/ }\end{array}$ & $2(17 \%)$ & $2(17 \%)$ \\
immunosuppressants & $9(60 \%)$ & $6(40 \%)$ \\
Infliximab & $8(53 \%)$ & $5(33 \%)$ & \\
\hline
\end{tabular}

animal research committee (Certificate E. 44011; Inserm, Nantes, France). Every effort was made to minimize animal suffering and the number of animals used. Rats were killed by an overdose of $\mathrm{CO}_{2}$ followed by severing of the carotid arteries. Intestinal cells obtained after dissection and dissociation were counted and then seeded at a density of $2.4 \times 10^{5}$ cells cm ${ }^{2}$ on 24-well plates (Corning, Avon, France) previously coated with a $0.5 \%$ gelatin solution (Sigma-Aldrich, Lyon, France). Primary cultures were maintained for 14 days with half of the medium replaced every day (Dulbecco's modified Eagle medium-F12 1:1 containing $1 \% \mathrm{~N}-2$ supplement (Life Technologies, Cergy Pontoise, France). Primary cultures were treated for $24 \mathrm{~h}$ with $0.1 \mu \mathrm{g} / \mathrm{mL}$ LPS (Sigma-Aldrich, Lyon, France) with or without $95 \mu \mathrm{M}$ AT-56 (provided by Y Urade; Osaka Bioscience Institute) a selective and competitive inhibitor of L-PGDS [27]. Three experiments were performed. The ENS culture media were collected, centrifuged and stored at $-80{ }^{\circ} \mathrm{C}$ for further analysis. For immunofluorescence staining, primary cultures of rats' ENS were fixed in $4 \%$ paraformaldehyde followed by several washes in phosphate buffer saline (PBS).

\section{Neuro-glial coculture model}

First, a glial feeder layer was made up from the enteric glial cell line JUG2 derived from the intestine of 15day-old rat embryos [28]. Briefly, the enteric glia were plated at a density of 7,500 cells $/ \mathrm{cm}^{2}$ in a 24-well plate, and maintained for 4 days in DMEM containing $10 \%$ fetal calf serum, $2 \mathrm{mM}$ glutamine, $50 \mu \mathrm{g} / \mathrm{ml}$ streptomycin and $50 \mathrm{UI} / \mathrm{ml}$ penicillin. The medium was replaced with serum-free Neurobasal/B27 medium (Gibco) $3 \mathrm{~h}$ before neuron culture. Rat enteric neuron culture was prepared from 15-day-old rat embryos by previously described methods [5], except that the dissociated cells were plated at 175,000 cells $/ \mathrm{cm}^{2}$ on glass coverslips coated with poly-L-lysine $(1 \mathrm{mg} / \mathrm{ml}$, Sigma) in DMEM high glucose containing $10 \%$ FCS, $2 \mathrm{mM}$ glutamine, $50 \mu \mathrm{g} / \mathrm{ml}$ streptomycin and $50 \mathrm{UI} / \mathrm{ml}$ penicillin. The coverslips were then transferred $3 \mathrm{~h}$ later to the wells containing the glial feeder layer and maintained for up to 7 days in Neurobasal/B27 containing $50 \mu \mathrm{g} / \mathrm{ml}$ streptomycin and $50 \mathrm{UI} / \mathrm{ml}$ penicillin. This procedure resulted in a culture on the coverslips composed of $82.6 \pm 5.5 \%$ of neurons and $10.6 \pm 3.6 \%$ of myofibroblasts, while no glial cells were detected (personal observation). This neuro-glial coculture system made it possible to physically separate the enteric neurons and the glial cells in order to examine the response of each cell type to LPS treatment.

\section{RT-PCR analysis}

Total RNA was extracted from human mucosal biopsies using the Nucleospin RNA/Protein kit (MachereyNagel, Hoerdt, France). cDNA was synthesized using standard procedures as previously described [24]. Realtime PCR was performed according to previous reports with some modifications [29]. Primers were designed from the sequence of human cDNAs using the Universal Probe Library assay design center (https://lifescience.roche.com/webapp/wcs/stores/servlet/CategoryDisplay?tab $=$ Assay + Design + Center\&identifier $=$ Universal + Probe+Library\&langId $=-1$ ); sequences are reported in Table 2. Amplification conditions of cPLA2-alpha, COX1, COX2, IL1B, TNF-alpha, L-PGDS, HPGDS, Dtype prostanoid (DP) receptor 1 and 2 (DP1, DP2), PPARG and MRPS6 templates were optimized for the Rotorgene 3000 instrument (Qiagen, Courtaboeuf, France). PCR amplifications were performed in duplicate using Light cycler 480 SYBR Green I master mix (Roche Diagnostics, Mannheim, Germany) according to the manufacturer's protocol. External standard curves were generated with serial 5-fold dilution of cDNA samples prepared with RNA extract from human mucosal biopsies. The relative amount of transcripts was calculated from these standard curves using RotorGene software. Expression of S6 ribosomal proteins as internal controls was analyzed at the same time. For each sample, the ratio between the relative amount of each specific transcript and S6 was calculated to compensate variations in the quantity and quality of starting mRNA.

\section{Immunofluorescence staining}

All antibodies were diluted in PBS with $1 \mathrm{mg} \mathrm{mL}{ }^{-1}$ sodium azide, $4 \%$ horse serum and $1 \%$ Triton X-100. Primary cultures of rat ENS, human plexi were incubated with PBS sodium azide horse serum and Triton X-100 followed by incubation with rabbit polyclonal anti-LPGDS (1:500; Cayman, Spi-Bio, Montigny-le-Bretonneux, 
Table 2 Primers for RT-PCR analysis

\begin{tabular}{|c|c|c|c|}
\hline Gene & $\begin{array}{l}\text { Accession } \\
\text { number }\end{array}$ & Species & $\begin{array}{l}\text { Primer sequences } \\
\left(5^{\prime}-3^{\prime}\right)\end{array}$ \\
\hline \multirow[t]{2}{*}{ TNF } & \multirow[t]{2}{*}{ NM_000594 } & \multirow{2}{*}{$\begin{array}{l}\text { Homo } \\
\text { Sapiens }\end{array}$} & Fw: CGCTCTTCTGCCTGCTGCACT \\
\hline & & & Rev: ACTGGAGCTGCCCCTCAGCTT \\
\hline \multirow[t]{2}{*}{ IL1B } & \multirow[t]{2}{*}{ NM_000576.2 } & \multirow{2}{*}{$\begin{array}{l}\text { Homo } \\
\text { Sapiens }\end{array}$} & Fw: AAAGCTTGGTGATGTCTGGTC \\
\hline & & & Rev : GGACATGGAGAACACCACTTG \\
\hline \multirow{2}{*}{$\begin{array}{l}\text { PTGS1 } \\
(\text { COX1) }\end{array}$} & \multirow[t]{2}{*}{ NM_000962.2 } & \multirow{2}{*}{$\begin{array}{l}\text { Homo } \\
\text { Sapiens }\end{array}$} & Fw: TCCTGTTGGTGGACTATGG \\
\hline & & & Rev: GTGGTGGTCCATGTTCCTG \\
\hline \multirow{2}{*}{$\begin{array}{l}\text { PTGS2 } \\
\text { (COX2) }\end{array}$} & \multirow[t]{2}{*}{ NM_000963.2 } & \multirow{2}{*}{$\begin{array}{l}\text { Homo } \\
\text { Sapiens }\end{array}$} & Fw: TGGGAAGCCTTCTCTAACCTC \\
\hline & & & Rev: TCAGGAAGCTGCTITITACCTT \\
\hline \multirow{2}{*}{$\begin{array}{l}\text { PLA2G4A } \\
\text { (cPLA2) }\end{array}$} & \multirow[t]{2}{*}{ NM_024420.2 } & \multirow{2}{*}{$\begin{array}{l}\text { Homo } \\
\text { Sapiens }\end{array}$} & FW: TGCTACCTACGTTGCTGGTCT \\
\hline & & & Rev: TTCTCTGGAAAATCAGGGTGA \\
\hline \multirow{2}{*}{$\begin{array}{l}\text { PTGDS } \\
\text { (L-PGDS) }\end{array}$} & \multirow[t]{2}{*}{ NM_000954.5 } & \multirow{2}{*}{$\begin{array}{l}\text { Homo } \\
\text { Sapiens }\end{array}$} & Fw: AGAAGAAGGCGGCGTTGTCC \\
\hline & & & Rev: CCACCACTGACACGGAGTAGG \\
\hline \multirow[t]{2}{*}{ HPGDS } & \multirow[t]{2}{*}{ NM_014485.2 } & \multirow[t]{2}{*}{$\begin{array}{l}\text { Homo } \\
\text { Sapiens }\end{array}$} & $\begin{array}{l}\text { Fw: } \\
\text { GAGAATGGCTTATTGGTAACTCTGT }\end{array}$ \\
\hline & & & $\begin{array}{l}\text { Rev: } \\
\text { AAAGACCAAAAGTGTGGTACTGC }\end{array}$ \\
\hline \multirow[t]{2}{*}{ MRPS6 } & \multirow[t]{2}{*}{ NM_001010 } & \multirow{2}{*}{$\begin{array}{l}\text { Human } \\
\text { mouse } \\
\text { rat }\end{array}$} & $\begin{array}{l}\text { FW: CCAAGCTTATTCAGCGTCTTGTTA } \\
\text { CTCC }\end{array}$ \\
\hline & & & $\begin{array}{l}\text { Rev: } \\
\text { CCCTCGAGTCCTTCATTCTCTTGGC }\end{array}$ \\
\hline \multirow{2}{*}{$\begin{array}{l}\text { PTGDR } \\
\text { (DP1) }\end{array}$} & \multirow[t]{2}{*}{ NM_000953 } & \multirow{2}{*}{$\begin{array}{l}\text { Homo } \\
\text { Sapiens }\end{array}$} & Fw: CCTGGAGGAGCGGATCA \\
\hline & & & Rev: GCTCCATAGTAAGCGCGATAAA \\
\hline \multirow{2}{*}{$\begin{array}{l}\text { PTGDR2 } \\
\text { (DP2) }\end{array}$} & \multirow[t]{2}{*}{ NM_004778 } & \multirow{2}{*}{$\begin{array}{l}\text { Homo } \\
\text { Sapiens }\end{array}$} & Fw: CCTGTGCTCCCTCTGTGC \\
\hline & & & Rev: TCTGGAGACGGCTCACTG \\
\hline \multirow[t]{2}{*}{ PPARG } & \multirow[t]{2}{*}{ NM_138711.3 } & \multirow[t]{2}{*}{$\begin{array}{l}\text { Homo } \\
\text { Sapiens }\end{array}$} & $\begin{array}{l}\text { FW: } \\
\text { AAAGTCGTCCTTCCCGCTGACCAAA }\end{array}$ \\
\hline & & & Rev: GATGGCCACCTCTITGCTCTGC \\
\hline
\end{tabular}

France) or with human polyclonal anti-HPGDS (1:500; Cayman Spi-Bio, Montigny-le-Bretonneux, France) overnight at $4{ }^{\circ} \mathrm{C}$. After extensive rinsing in PBS, primary culture or human tissues were incubated with donkey anti-Rabbit IgG conjugated with carboxymethyl-indocyanin (1:500; Beckman Coulter, Roissy, France) and donkey anti-human IgG conjugated with carboxy-methyl-indocyanin (1:500; Molecular Probes) for $3 \mathrm{~h}$ at room temperature. After L-PGDS and HPGDS staining, primary culture or human tissues were incubated with goat polyclonal anti-S100 $\beta$ (1:100; Santa-Cruz, Tebu-Bio, Le Perrayen Yveline, France) or with mouse anti-Hu (1:200 Molecular Probes) overnight at $4{ }^{\circ} \mathrm{C}$ followed by donkey anti-goat IgG conjugated with alexa Fluor 488 (1:400; Molecular Probes), donkey anti-mouse IgG conjugated with Alexa Fluor 488 fluorescent (1:500; Molecular Probes). Following washes, stained samples were observed and acquired with a IX 50 microscope (Olympus).
PGD2 assay

PGD2 levels in colonic mucosal biopsies of CD patients or released from cell culture in incubation medium were determined using the Prostaglandin D2-MOX EIA kit (Cayman Chemical, MI, USA). For colonic mucosal biopsies, acetone extraction was performed prior to deproteinization and to concentration. Biopsies were ground in $500 \mu \mathrm{l}$ cold acetone on ice. Precipitated proteins were removed by centrifuging at 3,000 g for $10 \mathrm{mi}-$ nutes. The sample was then evaporated to dryness under a stream of nitrogen gas. Finally, the sample was resuspended in $100 \mu$ l buffer and methoximation was performed according to the assay protocol.

\section{Statistical analysis}

Statistical analyses were performed using Prism 4.0 (GraphPad Software Inc., La Jolla, USA). Experimental data were compared using a non-parametric MannWhitney test, Kruskall-Wallis test followed by Dunn's post hoc test, Spearman test or Wilcoxon paired test. A $p$ value $<0.05$ was considered to be significant.

\section{Results}

mRNA expression of proinflammatory cytokines is increased in colonic biopsies from patients with active CD To determine the inflammatory status of the colonic biopsies from different groups of patients, we measured mRNA expression of proinflammatory cytokine tumor necrosis factor-alpha (TNF-alpha) and interleukin1, beta (IL1B). TNF-alpha mRNA was significantly increased in patients with active disease compared to healthy subjects and patients with quiescent disease (Fig 1a). Five patients with quiescent disease also presented with an increase in TNF-alpha expression. This transcriptional status was equivalent to that of patients with active CD. This increase was not associated with any relevant clinical characteristics or treatment. IL1B mRNA was significantly increased in sites of intestinal inflammation in patients with active $\mathrm{CD}$ compared to the other three groups: controls, biopsies from patients with quiescent disease and from normal mucosa of patients with active CD (Fig 1b).

\section{L-PGDS mRNA expression and PGD2 levels were increased in inflamed colonic mucosa of patients with active $C D$}

We then examined mRNA expression of the five key enzymes involved in PGD2 production and its receptors. Cytoplasmic Phospholipase A2 (cPLA2-alpha) and COX1 were up-regulated in the mucosa of patients with active $\mathrm{CD}$ and in the mucosa of five patients with quiescent disease (Fig 2a-b). In patients with active CD, COX2 mRNA expression was significantly increased in the inflamed zone compared to the normal zone (Fig 2c). Colonic expression 

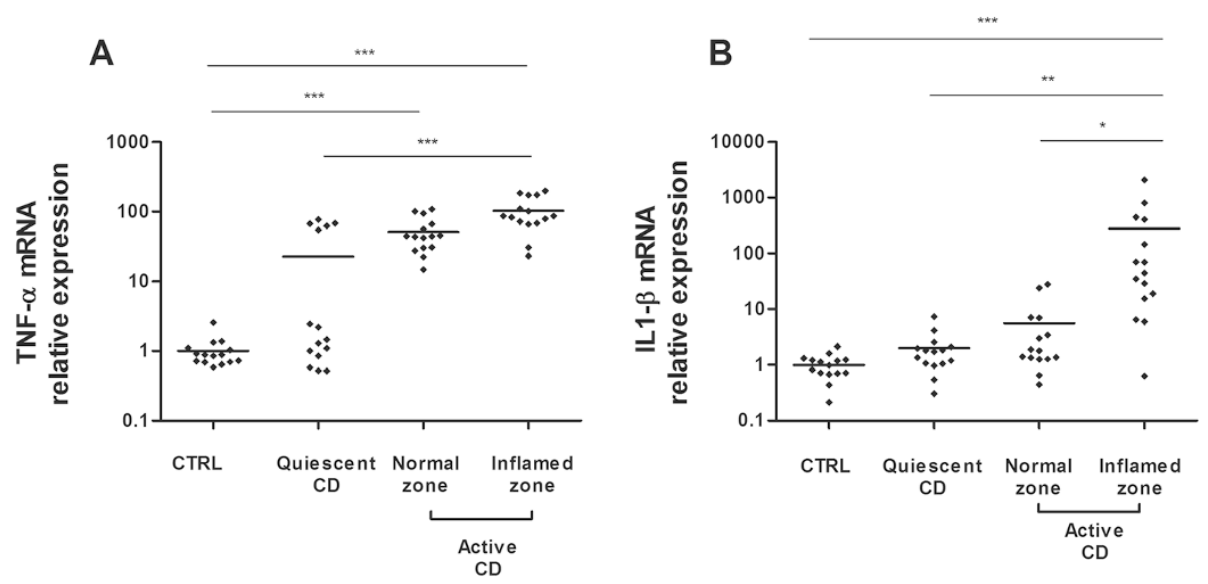

Fig. 1 Quantitative RT-PCR analysis of TNF-alpha (a) and IL1B (b) gene expression in colonic biopsies from healthy subjects (CTRL), CD patients with quiescent disease or active disease (normal zone and inflamed zone). Data were normalized to MRPS6 gene expression $\left(n=15\right.$; ${ }^{* * *} p<0.001$; ${ }^{* *} p<0.01 ;{ }^{*} p<0.5$, Kruskall-Wallis test followed by Dunn's post hoc test)

of HPGDS in colonic biopsy specimens from patients with quiescent $\mathrm{CD}$ did not differ significantly from that of controls (Fig 2d). HPGDS mRNA levels were reduced in the inflamed zone of patients with active CD. L-PGDS mRNA expression was significantly higher in the inflamed colonic mucosa of patients with active CD than in normal mucosa of $\mathrm{CD}$ patients or controls (Fig 2e). TNF-alpha mRNA expression was significantly correlated with cPLA2-alpha $(r=0.8245 ; p<0.0001)$ and COX1 $(r=0.84 ; p<0.0001)$ expression while IL1B mRNA expression was significantly correlated with COX2 $(r=$ $0.82, p<0.0001)$ and L-PGDS $(r=0.48 ; p<0.0001)$ expression. Only the inflamed zone in active CD showed total activation of the PGD2 metabolic pathway with up-regulation of cPLA2-alpha, COX1, COX2 and L-PGDS.

We quantified DP1, DP2 and PPARG mRNA expression in the same samples (Fig 3). The colonic expression of DP1 and DP2 in colonic biopsy specimens from patients with $C D$ did not differ significantly from that of controls except for the expression of DP2 which was reduced in inflamed colonic mucosa of $C D$ patients with active disease compared with mucosa of $C D$ patients with quiescent disease (Fig 3a-b). PPARG expression was reduced in inflamed colonic mucosa of $\mathrm{CD}$ patients with active disease compared with noninflamed mucosa of $\mathrm{CD}$ patients with active disease, mucosa of CD patients with quiescent disease or control mucosa (Fig 3c).

To determine whether activation could lead to higher PGD2 production, we measured PGD2 levels in the colonic biopsies of $C D$ patients. In patients with active $C D$, PGD2 levels were significantly higher in inflamed colonic mucosa than in normal colonic mucosa (Fig 4).
Neurons of the enteric nervous system express Lipocalin prostaglandin $\mathrm{D}$ synthase

L-PGDS expression by EGCs has been previously described [23]. To determine whether enteric neurons could also express L-PGDS, the main enzyme responsible for PGD2 synthesis in inflammatory conditions, we performed L-PGDS immunofluorescence labeling in human myenteric (Fig 5a) and in human submucosal plexi (Fig 5b). Neurons were selectively stained using antibodies directed against the neuronal protein $\mathrm{Hu} \mathrm{C} / \mathrm{D}$. We found that L-PGDS was expressed in neurons of both human myenteric and submucosal plexi. HPGDS was not expressed by ENS components (data not provided).

\section{ENS produced PGD2 via L-PGDS in proinflammatory conditions}

First, L-PGDS expression by glial and neuronal cells in rat ENS primary culture was verified by immunostaining (Fig 6a-b). In contrast, HPGDS was not detected in rat ENS primary culture (data not provided). In order to evaluate the capacity of the ENS to produce PGD2 in proinflammatory conditions, primary cultures were treated for 24 h with LPS without or with AT-56, a specific competitive L-PGDS inhibitor. LPS was used to induce an inflammatory stress. We showed that $1 /$ the ENS produced PGD2 in response to LPS, and 2/ at the IC50 concentration $(95 \mu \mathrm{M})$ AT-56 reduced PGD2 production in response to LPS (Fig 7a). These results confirmed that the ENS is able to produce PGD2 in proinflammatory conditions through L-PGDS. To determine the contribution of neurons and glial cells to the production of PGD2, a neuro-glial coculture model, in which neurons were plated on a glass coverslip suspended above a glia layer, was treated with LPS for $24 \mathrm{~h}$. 

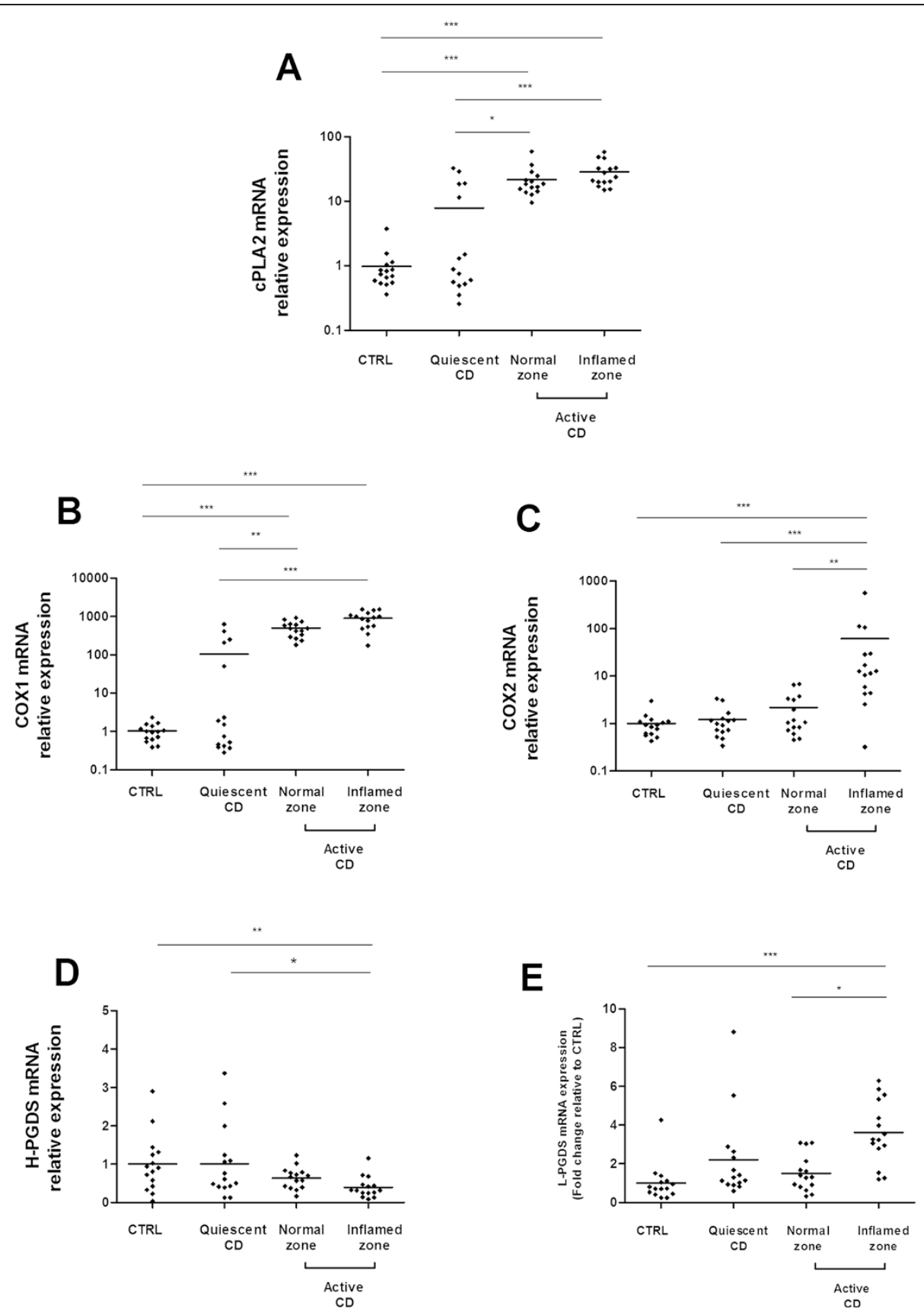

Fig. 2 Quantitative RT-PCR analysis of CPLA2 (a), COX1 (b), HPGDS (c), COX2 (d), L-PGDS (e), gene expression in colonic biopsies from healthy subjects (CTRL), CD patients with quiescent disease or active disease (normal zone and inflamed zone). Data were normalized to MRPS6 gene expression $\left(n=15 ;{ }^{* * *} p<0.001 ;{ }^{* *} p<0.01 ;{ }^{*} p<0.5\right.$, Kruskall-Wallis test followed by Dunn's post hoc test)

LPS treatment of the coculture model induced increased PGD2 production, as observed with ENS primary culture (Fig 7b). After 6 days' co-culture, glial cells and neurons were then separated and treated with LPS for $24 \mathrm{~h}$ (Fig 7c-d). We observed increased PGD2 production in isolated neurons and glial cells, suggesting that both enteric neurons and EGCs were able to produce PGD2 in proinflammatory conditions.

\section{Discussion}

Our work showed for the first time that there is activation of the entire PGD2 metabolic pathway by increase in mRNA expression of cPLA2-alpha, COX1, COX2 and L-PGDS in the inflamed zone of the colonic mucosa in active CD. Activation leads to increased PGD2 levels in inflamed colonic mucosa. Furthermore, our results showed that the ENS, both cellular components, 


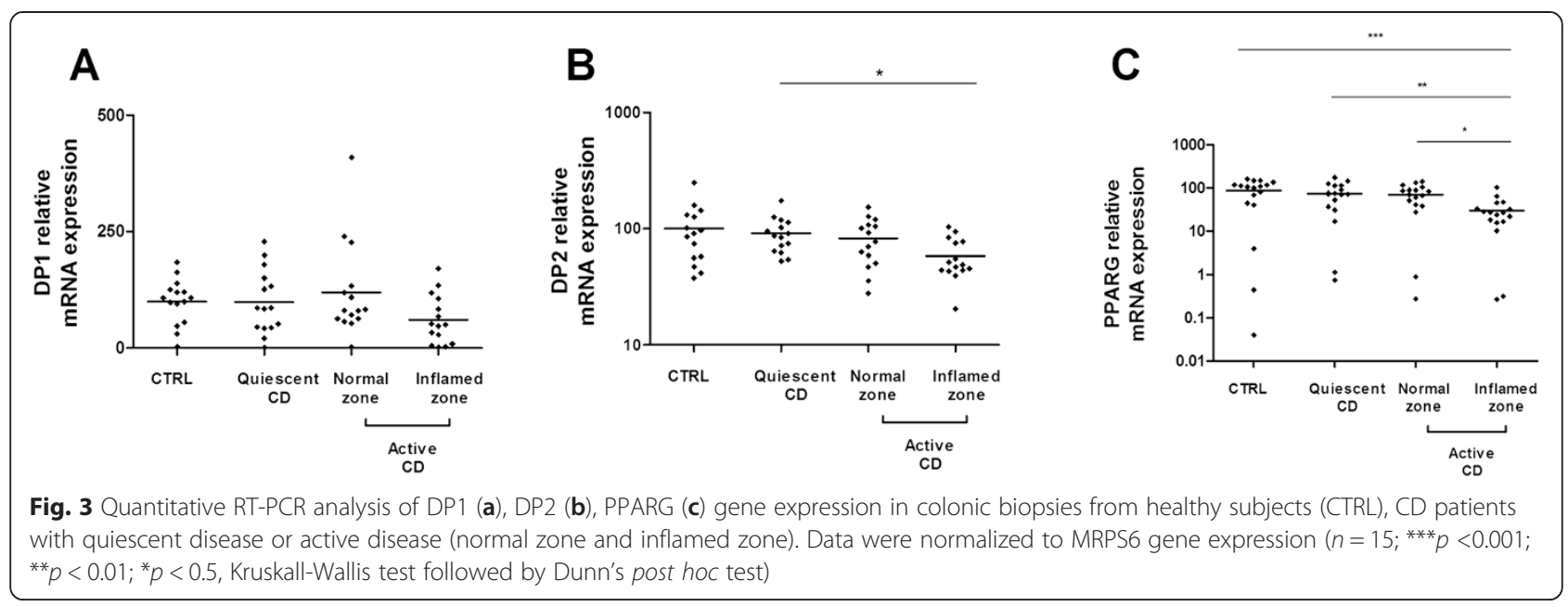

ECG and neurons, can contribute to PGD2 production in response to proinflammatory stress.

In colonic biopsies of $\mathrm{CD}$ patients, we reported two activation profiles respectively associated with TNFalpha and IL1B proinflammatory cytokines expression: a total activation profile involving TNF-alpha, IL1B, cPLA2-alpha, COX1, COX2 and L-PGDS, and intermediate activation profile, involving TNF-alpha, cPLA2alpha and COX1 observed both in the normal zone of colonic mucosa in active and quiescent $\mathrm{CD}$. This intermediate profile is found in the normal zone of colonic mucosa in the 15 patients with active CD but only in 5 patients with quiescent $\mathrm{CD}$. Among quiescent patients, these five patients did not show any obvious clinical differences from other quiescent patients. These five patients presented a transcriptional status equivalent to that of active CD patients. No histological analysis was done on these colonic biopsy specimens. Such analysis

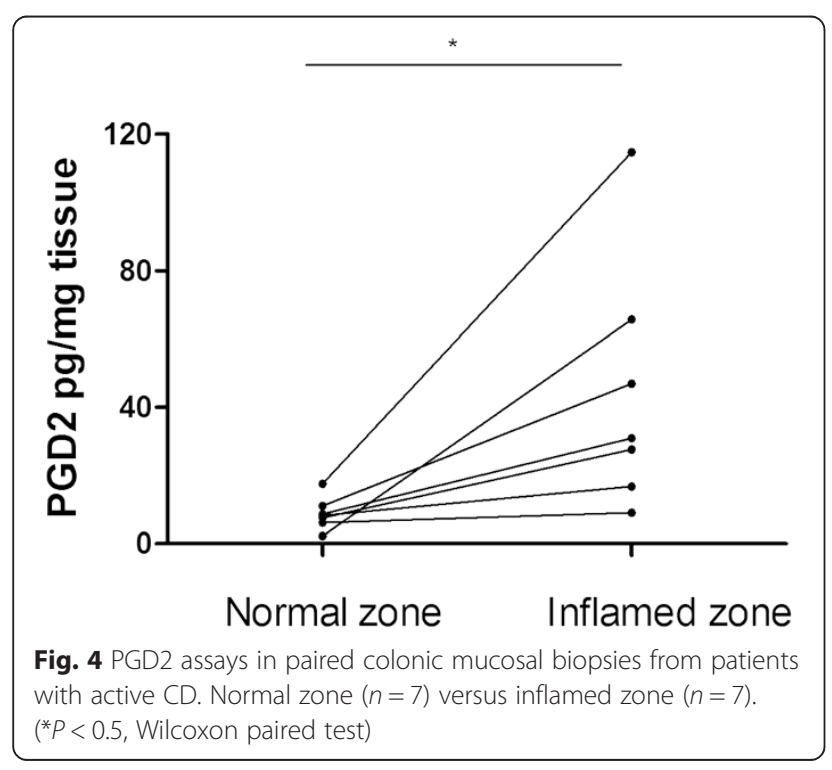

could clarify this result which could be secondary to the accumulation of inflammatory cells in the tissue. On the other hand, to identify other actors implicated in the signaling pathways involved in these two distinct inflammatory profiles, it would be interesting to compare the transcriptome of patients with active and quiescent $C D$ by performing microarray studies.

Interestingly, COX1 mRNA expression was upregulated in all patients with active $\mathrm{CD}$ and in five patients with quiescent $\mathrm{CD}$. COX1 is usually known to be a constitutive enzyme playing physiological roles, not involved in inflammatory responses [30]. However, high expression of COX1 has already been reported in gastric mucosa in inflammatory situations, where COX1-activity was involved in thromboxane A2 (TXA2) synthesis [31]. Hawkey et al. have reported increased TXA2 synthesis in non-inflamed rectal mucosa of $\mathrm{CD}$ patients [32], suggesting that COX1-TXA2 activation, leading to platelet aggregability and local vasoconstriction, is also of importance in CD. Therefore, COX1 and COX2 are probably both involved in mucosal integrity through different lipid mediators.

In accordance with a previous study [33, 34], we showed up-regulation of IL1B and COX2 expression in the inflamed zone of the colon in patients with active CD. A significant increase in mucosal expression of COX2, the main enzyme responsible for PG production in inflamed mucosa had been already reported [33, 34]. Here, we showed, for the first time, an up-regulation of L-PGDS expression and an increased synthesis of PGD2 in CD. Our data are in keeping with recent results from Hokari et al. in UC [12]. They demonstrated that LPGDS was up-regulated in severely inflamed mucosa and correlated with disease activity, suggesting inflammatory action. The mechanism by which the L-PGDS gene is up-regulated in inflammatory situations is partially described. Fujimory et al. demonstrated that L- 

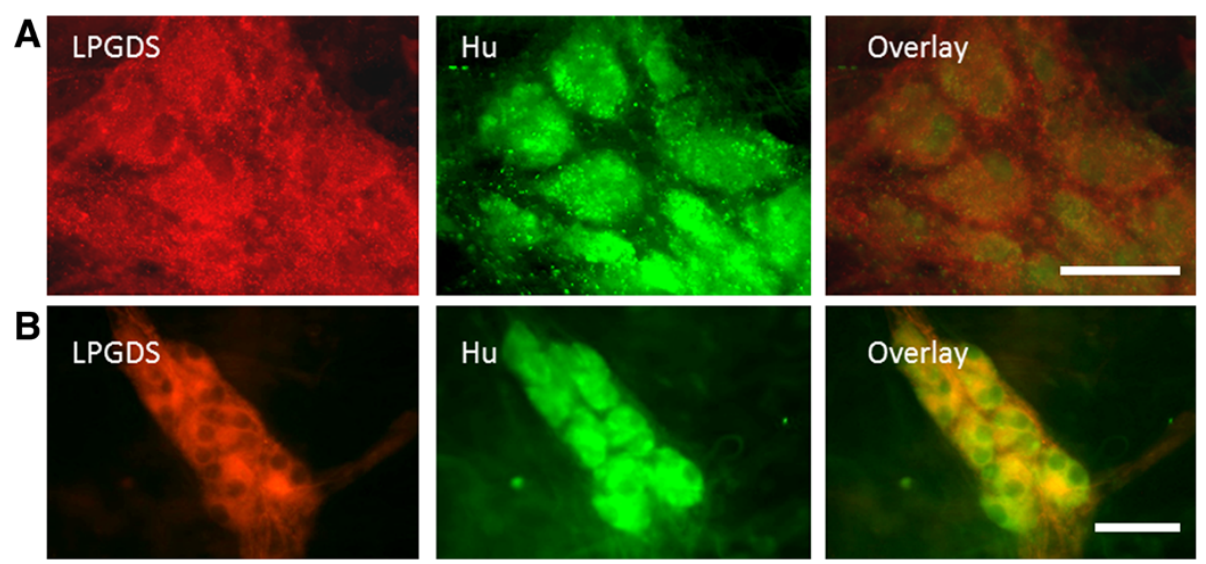

Fig. 5 Immunofluorescence staining of L-PGDS in human plexi. In human myenteric (a) and submucosal plexi (b), Hu was colocalized with L-PGDS Scales bars are $40 \mu \mathrm{m}(\mathbf{a}-\mathbf{b})$. Typical picture of four colonic tissues obtained in healthy area of two patients who underwent surgery for colonic adenocarcinoma

PGDS gene expression is up-regulated by IL-1 $\beta$ [35]. In rats, two NF-Kappa B elements, present on the L-PGDS gene promoter region, are essential to up-regulation. Conversely, HPGDS expression was not increased in the inflamed mucosa of patients with active disease. In the gut, although HPGS is the most important form of PGDS, expressed by intestinal epithelial cells, mast cells and fibroblasts [7, 36], our data suggests that PGD2 derived from L-PGDS plays a greater role in the pathophysiology of CD.

In our study, we showed that PPARG is down regulated in inflamed colonic mucosa of $\mathrm{CD}$ patients with active disease. The colonic expression of the two distinct PGD2 receptors DP1 and DP2 in colonic biopsy specimens from patients with $C D$ did not differ significantly from that in controls except for the expression of DP2 specifically reduced in inflamed colonic mucosa of $C D$ patients with active disease compared with mucosa of
CD patients with quiescent disease. The biological effect of PGD2 on intestinal inflammation remains widely debated. Only, few studies analyzed the role of PGD2 in an intestinal inflammatory process, with opposite roles $[5,6,37,38]$. Functional duality of PGD2 is probably based on the differential expression in human IBD of the three potential receptors activated by PGD2 or its metabolite, 15dPGJ2. 15dPGJ2 plays an anti-inflammatory or immunomodulatory role through PPARG, which is expressed at high levels in the colonic epithelium. The downregulation of PPARG suggests the inability of 15dPGJ2, PGD2 metabolite, to execute completely its antiinflammatory effects. The two distinct PGD2 receptors DP1 and DP2 are G protein coupled but signal via different second messengers. Engagement of DP1 results in protein kinase A activation [39] while DP2 acts to raise intracellular calcium levels [40]. PGD2 and 15dPGJ2 are both ligands for DP1 and DP2 [41]. Activation of DP1
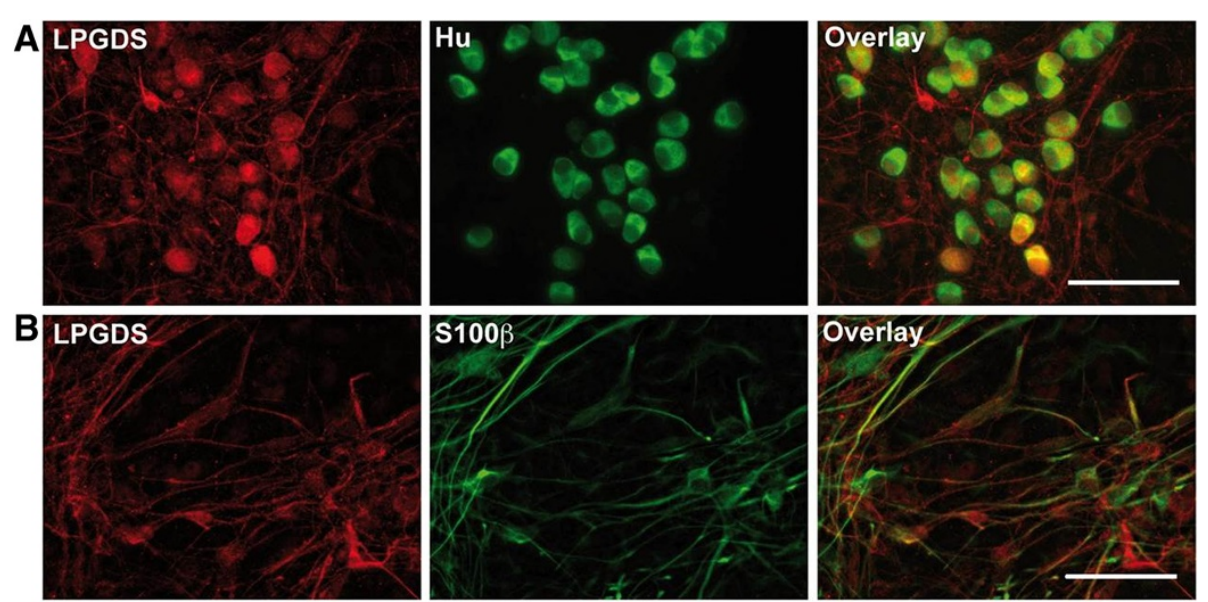

Fig. 6 Immunofluorescence staining of L-PGDS in primary culture of rat ENS. In primary culture of rat ENS, Hu (a) and S100ß (b) were colocalized with L-PGDS. Scales bars are $50 \mu \mathrm{m}$ (A-B) 

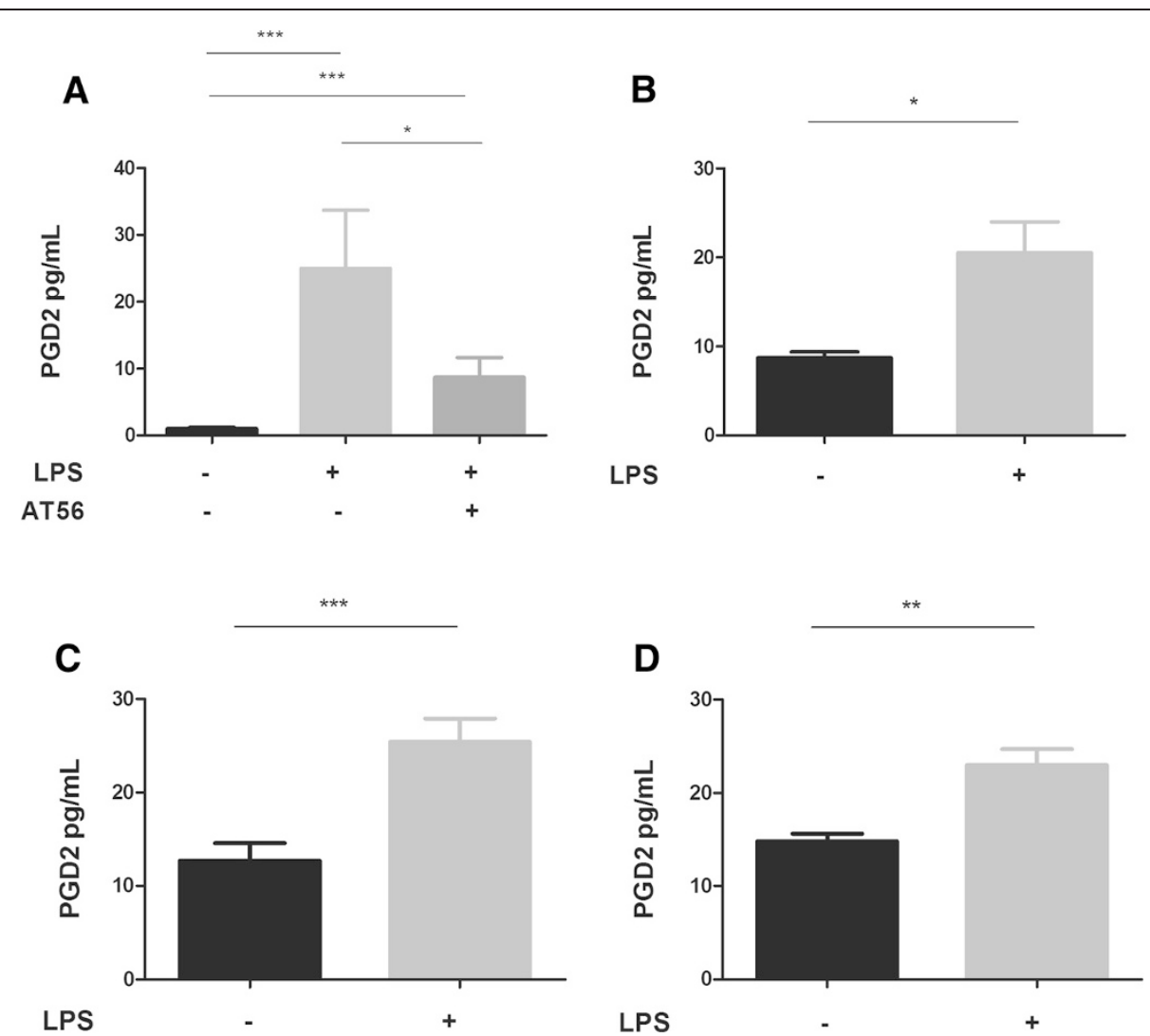

Fig. 7 Enteric nervous system and PGD2 production in inflammatory conditions. Primary culture of ENS with and without LPS $+/-$ AT-56 $(95 \mu \mathrm{M})(\mathbf{a})(n=12)$; coculture of ECG with neurons +/- LPS (b), EGCs culture +/- LPS (c), Neurons culture +/- LPS (d). Data were expressed as mean +/- SEM $(n=8)$, (Kruskall-Wallis test followed by Dunn's post hoc test was used for Fig. 6a, Mann-Whitney test was used for Fig $6 \mathbf{b}, \mathbf{c}, \mathbf{d}$ )

leads to beneficial effects. Reduction of granulocyte infiltration through DP1 activation was observed in a colitis model [5]. In colon biopsies of patients with UC, Vong et al. reported that PGD2 contributes to maintaining remission in patients. They observed increased PGD2 synthesis and increased DP1 receptor expression [6]. Some studies also showed that DP1 receptor activation stimulates mucin secretion, MUC2 and MUC5AC $[42,43]$. The main function of mucins is to protect the colonic mucosa [44]. MUC2 and MUC5AC are involved in epithelial repair in IBD by acting on cell differentiation and growth [45]. The beneficial role of PGD2 in CD may also be attributed to DP1 activation. PGD2 also plays an important role through DP2 activation by downregulating neutrophil infiltration into the mucosa in acute colitis. In a sepsis mouse model, PGD2 and $15 \mathrm{dPGJ} 2$ were significantly increased in peritoneal fluid. Furthermore, COX2 and L-PGDS were up-regulated in the peritoneal exudate cells. In this model, DP2-/mice exhibited a significantly higher accumulation of neutrophils into the peritoneal cavity compared with wild type mice [40].
Our study provides evidence on the origin of PGD2 in colitis. Enteric neurons and enteric glial cells are potent modulators of the intestinal epithelial barrier (IEB) and are involved in pathologies associated with altered barrier functions. EGC and neurons produce soluble factors known to regulate intestinal epithelial barrier functions $[14,21,24,46]$. PGD2 also seems to play a role in this relationship. Previously, we reported that EGCs express L-PGDS and are a cellular source of 15dPGJ2, which regulate epithelial cell proliferation and differentiation via PPARG activation [23]. Here, we first demonstrated that enteric neurons express L-PGDS but not HPGDS. Secondly, we showed that neurons and glial cells secrete PGD2 through L-PGDS in proinflammatory conditions. Thus, the ENS is a source of PGD2 in response to inflammatory stress which regulates IEB functions.

These data are consistent with the ENS's involvement in IBD pathogenesis. Altogether, enteric neurons, enteric glial cells and the IEB constitute a functional entity, the digestive neuronal-glial-epithelial unit, based on physical proximity and paracrin relations between its components [14]. The ENS is known to regulate the gut homeostasis 
process, and, in particular, intestinal epithelial barrier functions, via the release of various mediators [14]. In colitis, epithelial function is impaired, leading to elevated bacterial translocation. In the submucosal plexus, neurons and glial cells expressing Toll-like receptor 4, may participate in an adaptative reaction and may be engaged in the defense responses of the intestinal barrier [47]. This cellular reaction is similar to the proinflammatory process named reactive astrogliosis in the central nervous system (CNS). Immediately after CNS injury, glial cells undergo rapid morphological changes. Interestingly, L-PGDS, which is expressed by glial cells in the central nervous system, participates in reactive gliosis in an autocrine or paracrine manner, and may have pathological implications in neuroinflammatory diseases.

\section{Conclusion}

Emerging data suggest that paracrine communication between enteric neurons, glial cells and IEC regulate key functions and is involved in controlling IEB homeostasis. The PGD2 metabolic pathway implicating L-PGDS appears to be activated in Crohn's disease. This study demonstrates that L-PGDS, expressed in intestinal neurons and glial cells, is up-regulated in the inflamed colonic mucosa of patients with active $\mathrm{CD}$. More detailed studies are necessary to elucidate the mechanism relating to involvement of the PGD2 pathway in $\mathrm{CD}$. The next step will be identification of PGD2 targets in the IEB. It may reveal new targeted therapeutic options in CD.

\footnotetext{
Abbreviations

CD: Crohn's Disease; CNS: Central Nervous System; COX: Cyclooxygenases; CPLA2-alpha: Cytoplasmic Phospholipase A2; DP: D-type prostanoid; ECGs: Enteric Glial Cells; ENS: Enteric Nervous System; HPGDS: Hematopoietic Prostaglandin D Synthase; IBD: Inflammatory bowel diseases; IL1B: Interleukin 1, beta; L-PGDS: Lipocalin-type Prostaglandin D Synthase; LPS: Lipopolysaccharide; MRPS6: Mitochondrial ribosomal protein S6; PG: Prostaglandins; PGD2: Prostaglandin D2; PGH2: Prostaglandin H2; PGDS: Prostaglandin D Synthase; PLA2G4A: Phospholipase A2, groupe IVA; PPARG: Peroxysome Proliferator-Activated Receptor Gamma; PTGDR: Prostaglandin D2 Receptor; PTGDR2: Prostaglandin D2 Receptor 2; PTGDS: Prostaglandin D2 synthase; PTGS1: Prostaglandin-endoperoxide synthase 1; PTGS2: Prostaglandinendoperoxide synthase 2; IEB: Intestinal Epithelial Barrier; qRT-PCR: Quantitative Reverse Polymerase Chain Reaction; TNF-alpha: Tumor Necrosis Factor-alpha; TXA2: Thromboxane A2; UC: Ulcerative Colitis.
}

\section{Competing interests}

The authors declare that they have no competing interests.

\section{Authors' contributions}

All authors approved the article before submission. AGLL, KBN and DM wrote the article. AGLL, KBN and DM analyzed and interpreted the data. $A G L L$ and KBN performed the statistical analysis. AB collected biopsies. HB and MRD participated in discussions and critical revisions of the manuscript. AGLL designed experimental activities and performed the experiments. MGD, $\mathrm{MN}$ and DM provided overall supervision for the project.

\section{Authors' information}

AGLL, PharmD, KBN, PharmD PhD and DM, PharmD PhD, MGD, PharmD PhD, are specialists in biochemistry.

$A B, M D P h D$, is a medical gastroenterologist.
$H B, P h D, M R D, P h D, M N, P h D$, are Reseachers in neurogastroentrology.

\section{Acknowledgments}

The authors would like to extend their thanks to Muriel Quignard-Lopes, Camille Pana, Julie Jaulin and Catherine Le Berre-Scoul for their participation in the experiments.

The authors also thank Dr. Y Urade who kindly provided AT-56, specific L-PGDS inhibitor.

This work was supported by grants from the INSERM (Institut national de la Santé et de la Recherche Médicale), Nantes University, and the Centre Hospitalier Universitaire (CHU) of Nantes.

\section{Author details}

${ }^{1}$ INSERM Unité 913, 1 rue Gaston Veil, Nantes F-44035, France. ${ }^{2}$ Université Nantes, 1 quai de Tourville, BP 13522, Nantes F-44035, France. ${ }^{3}$ Institut des Maladies de l'Appareil Digestif, 1 place Alexis Ricordeau, Nantes F-44093, France. ${ }^{4}$ Laboratoire de Biochimie, Institut de Biologie, CHU de Nantes, 1 place Alexis Ricordeau, Nantes F-44093, France.

Received: 23 March 2015 Accepted: 24 August 2015

Published online: 04 September 2015

\section{References}

1. Guo AY, Stevens BW, Wilson RG, Russell CN, Cohen MA, Sturgeon HC, et al. Early life environment and natural history of inflammatory bowel diseases. BMC Gastroenterol. 2014;14(1):216.

2. Strober W, Fuss I, Mannon P. The fundamental basis of inflammatory bowel disease. J Clin Invest. 2007;117(3):514-21.

3. Gould SR, Brash AR, Conolly ME. Increased prostaglandin production in ulcerative colitis. Lancet. 1977;2(8028):98.

4. Zamuner SR, Warrier N, Buret AG, MacNaughton WK, Wallace JL. Cyclooxygenase 2 mediates post-inflammatory colonic secretory and barrier dysfunction. Gut. 2003;52(12):1714-20.

5. Ajuebor MN, Singh A, Wallace JL. Cyclooxygenase-2-derived prostaglandin $D(2)$ is an early anti-inflammatory signal in experimental colitis. Am J Physiol Gastrointest Liver Physiol. 2000;279(1):G238-244.

6. Vong L, Ferraz JG, Panaccione R, Beck PL, Wallace JL. A pro-resolution mediator, prostaglandin $\mathrm{D}(2)$, is specifically up-regulated in individuals in long-term remission from ulcerative colitis. Proc Natl Acad Sci U S A. 2010;107(26):12023-7.

7. Hokari R, Nagata N, Kurihara C, Watanabe C, Komoto S, Okada Y, et al. Increased expression and cellular localization of lipocalin-type prostaglandin D synthase in Helicobacter pylori-induced gastritis. J Pathol. 2009;219(4):417-26.

8. Smith WL, DeWitt DL, Garavito RM. Cyclooxygenases: structural, cellular, and molecular biology. Annu Rev Biochem. 2000;69:145-82.

9. Arai Y, Arihiro S, Matsuura T, Kato T, Matsuoka M, Saruta M, et al. Prostaglandin E-major urinary metabolite as a reliable surrogate marker for mucosal inflammation in ulcerative colitis. Inflamm Bowel Dis. 2014;20(7):1208-16.

10. Rajakariar R, Hilliard M, Lawrence T, Trivedi S, Colville-Nash P, Bellingan G, et al. Hematopoietic prostaglandin D2 synthase controls the onset and resolution of acute inflammation through PGD2 and 15-deoxyDelta12 14 PGJ2. Proc Natl Acad Sci U S A. 2007;104(52):20979-84.

11. Gilroy DW, Colville-Nash PR, McMaster S, Sawatzky DA, Willoughby DA, Lawrence T. Inducible cyclooxygenase-derived 15-deoxy(Delta)12-14PGJ2 brings about acute inflammatory resolution in rat pleurisy by inducing neutrophil and macrophage apoptosis. Faseb J. 2003;17(15):2269-71.

12. Hokari R, Kurihara C, Nagata N, Aritake K, Okada Y, Watanabe C, et al. Increased expression of lipocalin-type-prostaglandin D synthase in ulcerative colitis and exacerbating role in murine colitis. Am J Physiol Gastrointest Liver Physiol. 2011;300(3):G401-408.

13. lizuka M, Konno S. Wound healing of intestinal epithelial cells. World J Gastroenterol. 2011;17(17):2161-71.

14. Neunlist M, Van Landeghem L, Mahe MM, Derkinderen P, des Varannes SB, Rolli-Derkinderen M. The digestive neuronal-glial-epithelial unit: a new actor in gut health and disease. Nat Rev Gastroenterol Hepatol. 2013;10(2):90-100.

15. Coquenlorge S, Duchalais E, Chevalier J, Cossais F, Rolli-Derkinderen M, Neunlist M. Modulation of lipopolysaccharide-induced neuronal response by activation of the enteric nervous system. J Neuroinflammation. 2014;11(1):202

16. Ruhl A. Glial cells in the gut. Neurogastroenterol Motil. 2005;17(6):777-90. 
17. Bush TG, Savidge TC, Freeman TC, Cox HJ, Campbell EA, Mucke L, et al. Fulminant jejuno-ileitis following ablation of enteric glia in adult transgenic mice. Cell. 1998;93(2):189-201.

18. von Boyen GB, Schulte N, Pfluger C, Spaniol U, Hartmann C, Steinkamp M. Distribution of enteric glia and GDNF during gut inflammation. BMC Gastroenterol. 2011;11:3.

19. Vasina V, Barbara G, Talamonti L, Stanghellini V, Corinaldesi R, Tonini M, et al. Enteric neuroplasticity evoked by inflammation. Auton Neurosci. 2006;126-127:264-72.

20. Villanacci V, Bassotti G, Nascimbeni R, Antonelli E, Cadei M, Fisogni S, et al. Enteric nervous system abnormalities in inflammatory bowel diseases. Neurogastroenterol Motil. 2008;20(9):1009-16.

21. Savidge TC, Newman P, Pothoulakis C, Ruhl A, Neunlist M, Bourreille A, et al. Enteric glia regulate intestinal barrier function and inflammation via release of S-nitrosoglutathione. Gastroenterology. 2007;132(4):1344-58.

22. Neunlist M, Van Landeghem L, Bourreille A, Savidge T. Neuro-glial crosstalk in inflammatory bowel disease. J Intern Med. 2008;263(6):577-83.

23. Bach-Ngohou K, Mahe MM, Aubert P, Abdo H, Boni S, Bourreille A, et al. Enteric glia modulate epithelial cell proliferation and differentiation through 15-deoxy-12,14-prostaglandin J2. J Physiol. 2010;588(Pt 14):2533-44.

24. Neunlist M, Aubert P, Bonnaud S, Van Landeghem L, Coron E, Wedel T, et al. Enteric glia inhibit intestinal epithelial cell proliferation partly through a TGF-beta1-dependent pathway. Am J Physiol Gastrointest Liver Physiol. 2007;292(1):G231-241.

25. Chevalier J, Derkinderen P, Gomes P, Thinard R, Naveilhan P, Vanden Berghe $P$, et al. Activity-dependent regulation of tyrosine hydroxylase expression in the enteric nervous system. J Physiol. 2008;586(7):1963-75.

26. Drummond GB. Reporting ethical matters in the Journal of Physiology: standards and advice. J Physiol. 2009;587(Pt 4):713-9.

27. Irikura D, Aritake K, Nagata N, Maruyama T, Shimamoto S, Urade Y. Biochemical, functional, and pharmacological characterization of AT-56, an orally active and selective inhibitor of lipocalin-type prostaglandin D synthase. J Biol Chem. 2009;284(12):7623-30

28. Van Landeghem L, Chevalier J, Mahe MM, Wedel T, Urvil P, Derkinderen P, et al. Enteric glia promote intestinal mucosal healing via activation of focal adhesion kinase and release of proEGF. Am J Physiol Gastrointest Liver Physiol. 2011;300(6):G976-987.

29. Blanchot-Jossic F, Jarry A, Masson D, Bach-Ngohou K, Paineau J, Denis $M G$, et al. Up-regulated expression of ADAM17 in human colon carcinoma: co-expression with EGFR in neoplastic and endothelial cells. J Pathol. 2005;207(2):156-63.

30. Smith WL, Urade Y, Jakobsson PJ. Enzymes of the cyclooxygenase pathways of prostanoid biosynthesis. Chem Rev. 2011;111(10):5821-65.

31. Wallace $J$, McKnight W, Reuter BK, Vergnolle N. NSAID-induced gastric damage in rats: requirement for inhibition of both cyclooxygenase 1 and 2 . Gastroenterology. 2000;119(3):706-14.

32. Hawkey CJ, Karmeli F, Rachmilewitz D. Imbalance of prostacyclin and thromboxane synthesis in Crohn's disease. Gut. 1983;24(10):881-5.

33. Reuter BK, Asfaha S, Buret A, Sharkey KA, Wallace JL. Exacerbation of inflammation-associated colonic injury in rat through inhibition of cyclooxygenase-2. J Clin Invest. 1996;98(9):2076-85.

34. McCartney SA, Mitchell JA, Fairclough PD, Farthing MJ, Warner TD. Selective COX-2 inhibitors and human inflammatory bowel disease. Aliment Pharmacol Ther. 1999;13(8):1115-7.

35. Fujimori K, Fujitani Y, Kadoyama K, Kumanogoh H, Ishikawa K, Urade Y. Regulation of lipocalin-type prostaglandin $D$ synthase gene expression by Hes-1 through E-box and interleukin-1 beta via two NF-kappa B elements in rat leptomeningeal cells. J Biol Chem. 2003;278(8):6018-26.

36. Park JM, Kanaoka Y, Eguchi N, Aritake K, Grujic S, Materi AM, et al. Hematopoietic prostaglandin D synthase suppresses intestinal adenomas in ApcMin/+ mice. Cancer Res. 2007;67(3):881-9.

37. Zamuner SR, Bak AW, Devchand PR, Wallace JL. Predisposition to colorectal cancer in rats with resolved colitis: role of cyclooxygenase-2-derived prostaglandin d2. Am J Pathol. 2005;167(5):1293-300.

38. Sturm EM, Radnai B, Jandl K, Stancic A, Parzmair GP, Hogenauer C, et al. Opposing roles of prostaglandin D2 receptors in ulcerative colitis. J Immunol. 2014;193(2):827-39.
39. Boie Y, Sawyer N, Slipetz DM, Metters KM, Abramovitz M. Molecular cloning and characterization of the human prostanoid DP receptor. J Biol Chem. 1995;270(32):18910-6.

40. Ishii M, Asano K, Namkoong H, Tasaka S, Mizoguchi K, Asami T, et al. CRTH2 is a critical regulator of neutrophil migration and resistance to polymicrobial sepsis. J Immunol. 2012;188(11):5655-64.

41. Nagata K, Hirai H. The second PGD(2) receptor CRTH2: structure, properties, and functions in leukocytes. Prostaglandins Leukot Essent Fatty Acids. 2003;69(2-3):169-77.

42. Choi YH, Lee SN, Aoyagi H, Yamasaki Y, Yoo JY, Park B, et al. The extracellular signal-regulated kinase mitogen-activated protein kinase/ ribosomal 56 protein kinase 1 cascade phosphorylates CAMP response element-binding protein to induce MUC5B gene expression via Dprostanoid receptor signaling. J Biol Chem. 2011;286(39):34199-214.

43. Wright DH, Ford-Hutchinson AW, Chadee K, Metters KM. The human prostanoid DP receptor stimulates mucin secretion in LS174T cells. Br J Pharmacol. 2000;131(8):1537-45.

44. Hansson GC. Role of mucus layers in gut infection and inflammation. Curr Opin Microbiol. 2012;15(1):57-62.

45. Buisine MP, Desreumaux P, Leteurtre E, Copin MC, Colombel JF, Porchet N, et al. Mucin gene expression in intestinal epithelial cells in Crohn's disease. Gut. 2001;49(4):544-51

46. Neunlist M, Toumi F, Oreschkova T, Denis M, Leborgne J, Laboisse CL, et al. Human ENS regulates the intestinal epithelial barrier permeability and a tight junction-associated protein ZO-1 via VIPergic pathways. Am J Physiol Gastrointest Liver Physiol. 2003;285(5):G1028-1036.

47. Barajon I, Serrao G, Arnaboldi F, Opizzi E, Ripamonti G, Balsari A, et al. Toll-like receptors 3, 4, and 7 are expressed in the enteric nervous system and dorsal root ganglia. J Histochem Cytochem. 2009;57(11):1013-23

\section{Submit your next manuscript to BioMed Central and take full advantage of:}

- Convenient online submission

- Thorough peer review

- No space constraints or color figure charges

- Immediate publication on acceptance

- Inclusion in PubMed, CAS, Scopus and Google Scholar

- Research which is freely available for redistribution 